\title{
Use of non-invasive sensor to assess intracranial compliance in the management of migraine patients: case report
}

Luiz Gabriel Gonçalves Cherain ( $\nabla$ Igcherain@gmail.com )

Faculdade Atenas https://orcid.org/0000-0003-0150-6348

Mateus Gonçalves de Sena Barbosa

Faculdade Atenas

Rafaela Luiza Vilela de Souza

Faculdade Atenas

Rafaela de Souza Paula

Faculdade Atenas

Geovana Ribeiro Campos

Faculdade Atenas

Isadora Silva

Faculdade Atenas

Elaine Peixoto

Brain4Care

Nícollas Nunes Rabelo

Faculdade Atenas

\section{Research Article}

Keywords: idiopathic intracranial hypertension, intracranial pressure, decision-making, technology, headache

Posted Date: December 14th, 2021

DOI: https://doi.org/10.21203/rs.3.rs-1162693/v1

License: (c) (i) This work is licensed under a Creative Commons Attribution 4.0 International License. Read Full License 


\section{Abstract}

The objective of this study is to report the use of a non-invasive sensor to assess intracranial compliance (ICC) in patients complaining of migraine. This case report presents a 34-year-old, female patient that was treated for idiopathic intracranial hypertension $(\mathrm{IIH})$ by placing a non-adjustable lumboperitoneal shunt. After one year, she presented with headache and signs of overdrainage. Non-invasive monitoring of ICC was done, suggesting a reduction in the ICC, but no change in the opening pressure of the valve. A diagnosis of migraine was made, with improvement after brain monitoring, leading treatment without any new surgical intervention. With this case, we conclude that the use of non-invasive sensor helped the medical team to understand the information obtained by the ICP curve in the office, and in the management of patients with headache complaints, supporting clinical decision making, improving the quality of care, correlated with underlying diseases and procedural and patient safety.

\section{Introduction}

Migraine is a disabling, multifactorial, hereditary disease caused by increased excitability of the central nervous system. Its origin is associated with a neurological disorder in multiple brain areas. Seizures last from a few hours to three days and usually begin with prodromes and aura transient focal neurological symptoms. The pain begins with the activation of meningeal nociceptors at the origin of the trigeminovascular system, responsible for transmitting this sympathetic and parasympathetic information to the brain. It can be initiated and aggravated by routine activities, such as irregular sleep and eating, stress, hormonal changes, alcohol intake, noises, lights, and aromas, which makes it incapacitating and decreases the patient's quality of life $(3,8,10)$.

The diagnosis is made based on the patient's anamnesis, clinical signs and symptoms, based on the criteria of the International Headache Society: the attack must be episodic; the duration must be between 4 to 72 hours; the headache must contain at least two of the following factors: unilateral, throbbing, aggravated by movement, moderate to severe pain, and the headache must present at least one of the following characteristics: nausea and vomiting or photophobia $(6,7)$.

In this report, we present a patient who benefited from non-invasive intracranial pressure (ICP) monitoring in the management of migraine in the late postoperative period of idiopathic intracranial hypertension $(\mathrm{IIH})$.

\section{Case Study}

A 34-year-old female patient, obese, in use of oral contraceptive was treated for IIH by placing a nonadjustable lumboperitoneal shunt with opening pressure of $60 \mathrm{~cm} \mathrm{H}_{2} \mathrm{O}$. After one year, she presented with headache and signs of overdrainage seen by magnetic resonance imaging (MRI) with contrast enhancement in the meninges. Probably, the system destabilized because the patient lost weight. After 6 months she stabilized and become asymptomatic. Two years after the surgery, she presented with typical 
migraine symptoms and a non-invasive intracranial compliance (ICC) monitoring was performed with Brain 4 Care ${ }^{\circledR}$ non-invasive sensor to assess intracranial compliance in the management of migraine. This non-invasive examen showed a curve with an altered ICC and a P2/P1 ratio of 1.21, suggesting a reduction in the ICC (figure 1). Although, there was no change in the opening pressure, the MRI maintained the same previous findings and the hemodynamic control remained stable.

Given the clinical context, she was treated with topiramate and propranolol for migraine symptoms. Additionally, ibuprofen, and dipyrone were used.

After one month drug treatment, with the clinical context of post IIH, a new ICP pulse monitoring was performed (figure 2), whose value was 1.36, however, this was justified by menstrual headache-pain. Therefore, the contraceptive was changed from oral contraceptive to an intrauterine device (IUD), and the prescribed medication was maintained.

After 3 months, the patient presented total improvement of the compliance and the migraine after the treatment (figure 3).

\section{Discussion}

Several diseases were considered and carefully eliminated to correctly diagnose the patient in question. Initially, the possibility of migraine-type headache (migraine) secondary to the recurrence of the IIH, was considered.

The non-invasive method of ICP assessment and compliance analysis, using the brain4care (B4C) device, was used for patient follow-up. To understand the results, it is necessary to know that the monitoring of ICP happens through the evaluation of the waves originated in each cardiac cycle, in which the blood flow is directed to the brain. Therefore, 3 waves are formed: P1 (percussion wave, which reflects the arterial pressure transmitted from the choroid plexus to the cerebral ventricle), P2 (tidal wave, related to intracranial compliance), P3 (dichroitic wave, related to the aortic valve closure during diastole), and for validation of a good result, the waves should remain P1>P2>P3.

Non-invasive monitoring of ICC in the office was performed and made it possible to exclude the hypothesis of intracranial hypertension $(\mathrm{ICH})$ due to an $\mathrm{IIH}$, since a mean P2/P1 ratio of 1.21 was verified, that is, the $\mathrm{P} 2$ component was higher than $\mathrm{P} 1$, suggesting reduced ICC, however, without alteration in the opening pressure of the cerebrospinal fluid (CSF). In the posterior consultation, without overweight, the patient referred a new episode of migraine, reporting being in her menstrual period accompanied by menstrual pain, and the non-invasive monitoring indicated a P2/P1 ratio of 1.36. The clinical view of the patient, her history of obesity and use of oral contraceptives (1) associated with the identification of decreased brain compliance without pressure change, by means of non-invasive monitoring, were determinant in the diagnosis of migraine, a multifactorial disease that has a strong hormonal influence $(2,4,5,9,11)$. Especially this case, the non-invasive monitoring was fundamental because, she had hydrodynamic disease, and the decision-making is really tough, when headache really appear after 
months of the treatment. In this case was possible to know exactly what was happen, and compare the treatments.

This study aims to show that diagnosis and treatment, as well as the evaluation of the ICP and ICC, can be made easier with the use of non-invasive monitoring in the doctor's office, avoiding hospital admissions and invasive procedures.

\section{Conclusion}

With this case, we conclude that the use of non-invasive sensor helped the medical team to understand the information obtained by the ICP curve in the office, and in the management of patients with headache complaints, supporting clinical decision making, improving the quality of care, correlated with underlying diseases and procedural and patient safety.

\section{Declarations}

\section{FUNDING}

No funding was received for this study.

\section{CONFLICT OF INTEREST}

The authors declare that they have no conflict of interest.

\section{ETHICS APPROVAL}

All procedures performed in the study involving human participants were in accordance with the ethical standards of the institution.

\section{INFORMED CONSENT}

Informed consent was obtained from the participant included in the study.

\section{CONSENT FOR PUBLICATION}

The participant has consented to the submission of the case report to the journal.

\section{References}

1. Aegidius K, Zwart J-A, Hagen K, Schei B, Stovner LJ. Oral contraceptives and increased headache prevalence: the Head-HUNT Study. Neurology. 2006 Feb 14;66(3):349-53.

2. Brandes JL. The influence of estrogen on migraine: a systematic review. JAMA. $2006 \mathrm{Apr}$ 19;295(15):1824-30. 
3. Burstein R, Noseda R, Borsook D. Migraine: multiple processes, complex pathophysiology. J Neurosci. 2015 Apr 29;35(17):6619-29. doi: 10.1523/JNEUROSCI.0373-15.2015. PMID: 25926442; PMCID: PMC4412887.

4. Faubion SS, Batur P, Calhoun AH. Migraine Throughout the Female Reproductive Life Cycle. Mayo Clin Proc. 2018 May;93(5):639-45.

5. Granella F, Sances G, Pucci E, Nappi RE, Ghiotto N, Napp G. Migraine with aura and reproductive life events: a case control study. Cephalalgia. 2000 0ct;20(8):701-7.

6. Joubert J. Enxaqueca- diagnóstico e tratamento. Aust Fam Doctor. 2005 Ago;34(8):627-32. 16113698.

7. Mallery RM, Friedman DI, Liu GT. Headache and the pseudotumor cerebri syndrome. Curr Pain Headache Rep. 2014 Sep;18(9):446. doi: 10.1007/s11916-014-0446-z. PMID: 25086688.

8. PORTO, C. C. Semiologia Médica. 8. ed. Rio de Janeiro: Guanabara Koogan, 2019

9. Sacco S, Ricci S, Degan D, Carolei A. Migraine in women: the role of hormones and their impact on vascular diseases. J Headache Pain. 2012 Apr;13(3):177-89.

10. Silberstein SD. Migraine. Lancet. 2004 Jan 31;363(9406):381-91. doi: 10.1016/S01406736(04)15440-8. PMID: 15070571.

11. Wöber C, Brannath W, Schmidt K, Kapitan M, Rudel E, Wessely P, et al. Prospective analysis of factors related to migraine attacks: the PAMINA study. Cephalalgia. 2007 Apr;27(4):304-14.

\section{Figures}

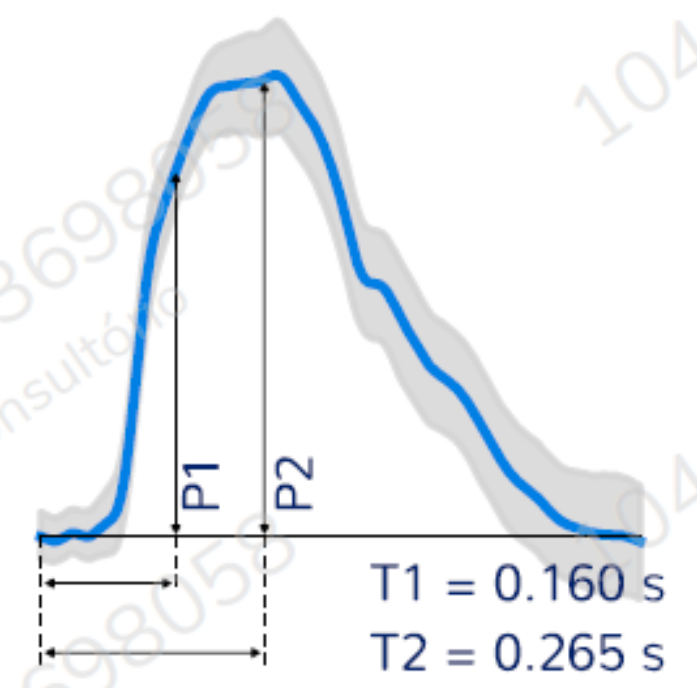

Rel. P2/P1 = 1.21[1.00, 1.43]

Pulsos úteis $=49$

$\mathrm{FC}=81[77,89] \mathrm{bpm}$

Time to Peak $=0.27[0.24,0.29]$ 
Figure 1

The altered ICP compliance curve in the first monitoring suggests an ICC reduction and represents a migraine headache.

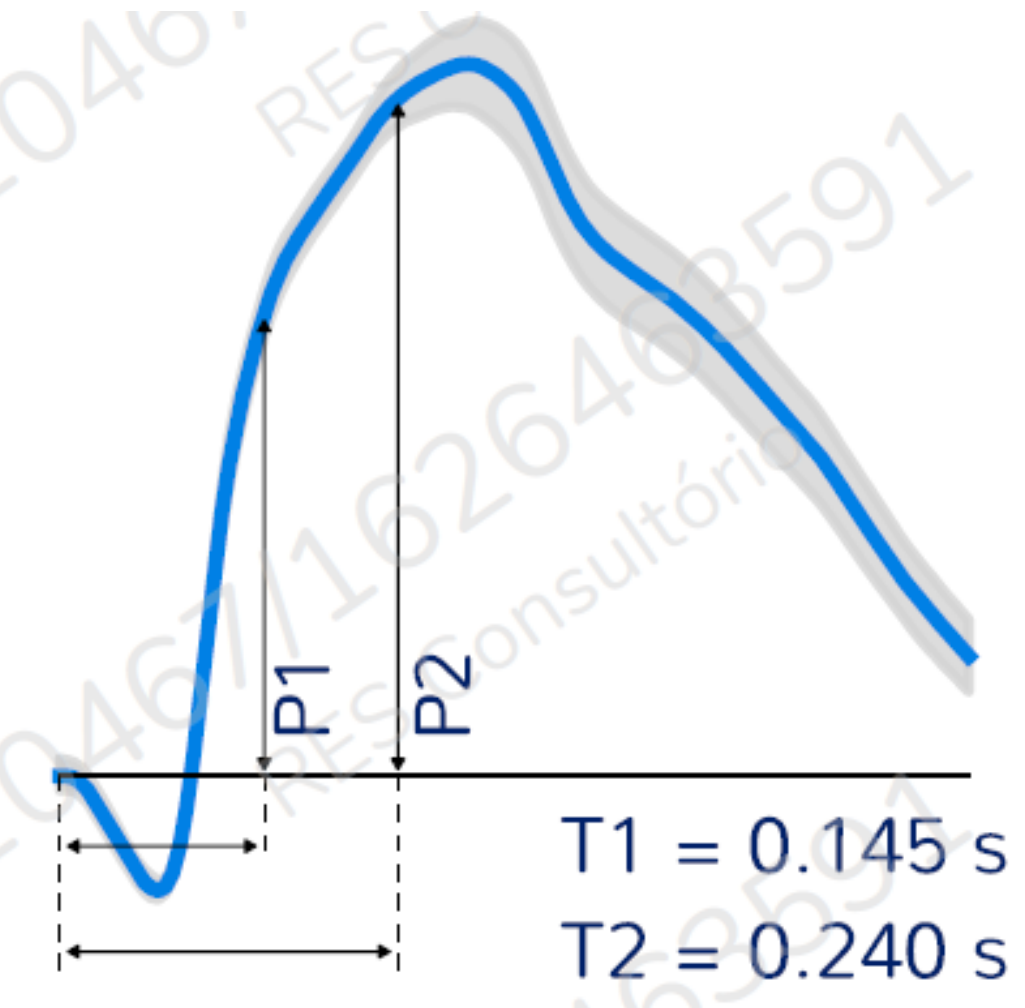

Rel. P2/P1 = 1.36[1.26, 1.47]

Pulsos úteis $=76$

$\mathrm{FC}=88[86,89] \mathrm{bpm}$

Time to Peak $=0.36[0.36,0.37]$

Figure 2

The second ICP monitoring. In this moment, the patient was in the menstrual period and with menstrual pain. 


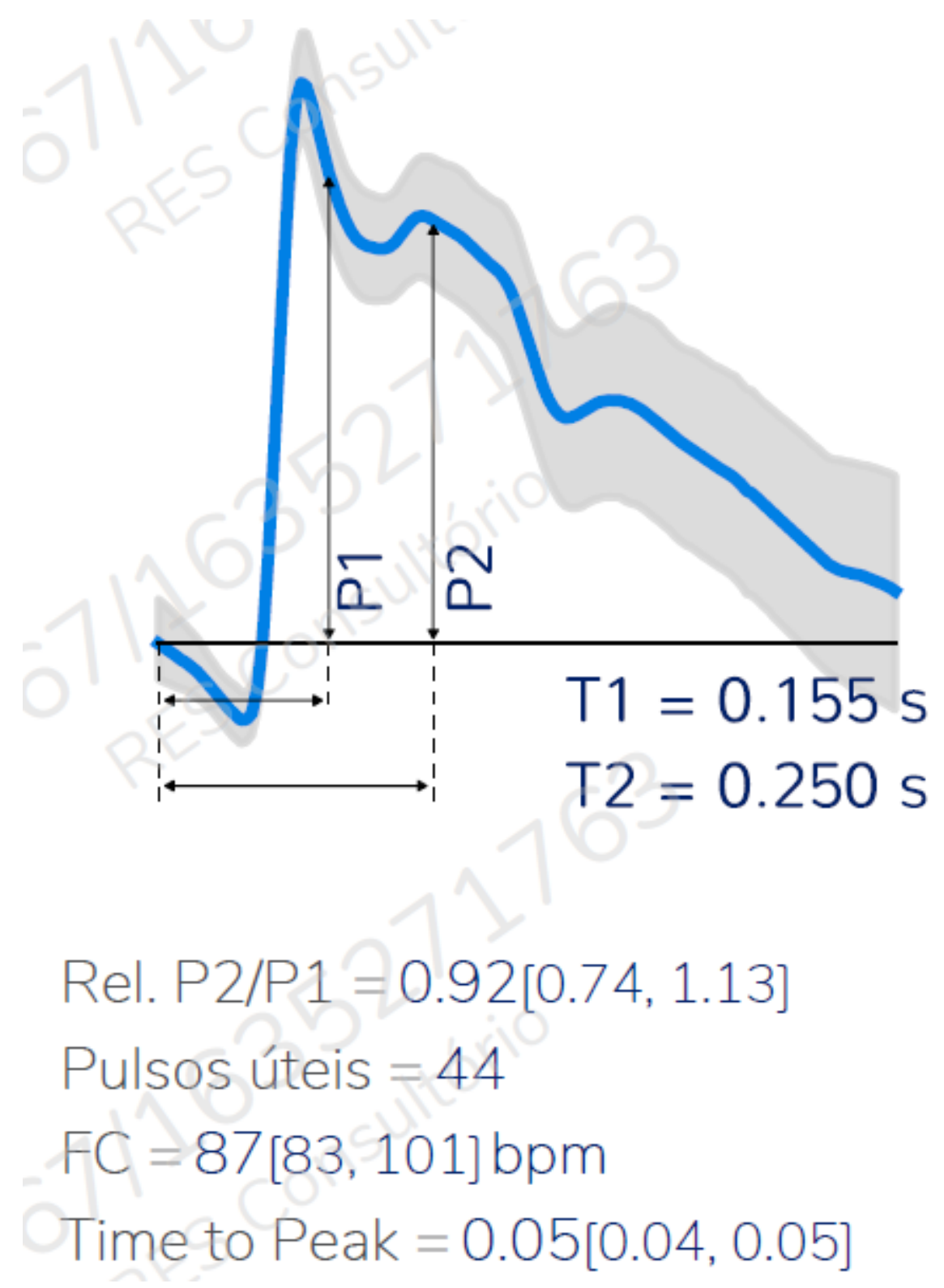

Figure 3

The ICP curve 3 months after the treatment showed a normal P2/P1 ratio (under 1.0), indicating recover of the patient symptoms. 